\title{
GESTÃO PÚBLICA NO BRASIL: NOTÍCIAS DO TEATRO DE OPERAÇÕES
}

\author{
Paula Chies Schommer
}

FGV-EAESP

\section{INTRODUÇÃo}

A gestão pública brasileira vive um intenso processo de transformação, desde a década de 1980, sob influência principal da redemocratização do país e da reforma do Estado, que tem na descentralização um de seus eixos principais. Novas relações entre níveis de governo e entre Estado e sociedade, com a participação de novos agentes na formulação, na implementação e no controle de políticas públicas, indicam mudanças nas práticas políticas e organizacionais e, ao mesmo tempo, exigem novos arranjos institucionais.

Em um momento em que o tema da mudança ganha espaço na abordagem institucional dos estudos organizacionais, parece oportuna a realização de estudos que tenham como objeto as recentes transformações na gestão pública brasileira. A proposta é indicar possíveis pontos de aproximação entre estudos organizacionais e gestão pública em uma perspectiva institucionalista, já que a sensação é de que há espaço para mais comunicação entre ambos.

Observando o caso brasileiro, defendemos que é possível superar características que, a priori, impediriam o avanço das práticas de gestão pública. Chamamos a atenção sobre o fato de instituições não serem estáticas e os processos de institucionalização e desinstitucionaliza- ção serem, em geral, complexos, dinâmicos, multifacetados, causados por mais de um fator e nem sempre contínuos, articulando de diversas maneiras o tradicional e o novo. Embora o isomorfismo seja tema clássico na teoria institucional, questionamos o quanto é possível falar em homogeneização se considerarmos as muitas variáveis que se combinam, articulam ou hibridizam, tanto para a manutenção quanto para a mudança de práticas, valores, estruturas e processos institucionalizados.

\section{A MUDANÇA INSTITUCIONAL EM FOCO NOS ESTUDOS ORGANIZACIONAIS}

A teoria institucional é freqüentemente criticada por enfatizar a repetição e a homogeneidade dos fenômenos, negligenciando a compreensão dos fatores de mudança e o papel dos interesses dos agentes nesses processos. O tema da mudança institucional, entretanto, está em alta na teoria organizacional. Na edição de fevereiro de 2002 do respeitado periódico The Academy of Management Journal, um fórum especial teve como proposta lançar luzes sobre como as instituições são criadas, transformadas e extintas e como os processos institucionais interagem para afetar a mudança institucional.
O significado do termo instituição pode variar conforme o objetivo, o objeto, a disciplina ou a perspectiva de análise. E considerar um objeto como instituição ou não depende do problema em estudo. Genericamente, podemos pensar em instituições como "as regras do jogo", respostas comuns à dada situação ou padrões estabelecidos, o que não significa que sejam estáticas.

Algo que está institucionalizado não corresponde a algo que não pode ser mudado, mas sim a alguma coisa que requer menos mobilização e intervenção para se sustentar. De natureza processual e dinâmica, padrões institucionalizados são, portanto, resultado de um particular e contínuo processo de reprodução, sujeitos à ação social dos atores para contestá-los, modificálos, eliminá-los, bem como para ampliar ou reduzir sua força ao longo do tempo. Um padrão institucionalizado é também referência para prêmios e sanções, de acordo com o grau de conformidade ao que está estabelecido. E o interessante é que as instituições são espaços que, ao mesmo tempo, permitem e limitam as atividades, constrangem e dão liberdade de ação, incentivam e controlam comportamentos.

As mudanças institucionais podem ser incrementais ou abruptas, com descontinuidade provocada por 
um conjunto de fatores contextuais ou por um evento dramático específico, uma ação desencadeadora. Os processos de desinstitucionalização, pelos quais práticas e normas institucionalizadas se enfraquecem e desaparecem, são provocados por pressões de natureza funcional, social ou política, ou, ainda, uma mistura delas. Podem resultar de questionamentos sobre desempenho ou utilidade de práticas estabelecidas, por fatores como a intensificação da competição por recursos, as inovações tecnológicas significativas, a diferenciação de grupos, as crenças e práticas heterogêneas ou discordantes, as mudanças em leis ou expectativas sociais, e a influência de novas concepções provenientes de contextos institucionais mais amplos. Entre os fatores de natureza política está a relação entre poder e instituições. Se entendermos que as disputas de poder geram as instituições, podemos dizer que a mudança ocorre quando se modificam os arranjos de poder internos e externos que davam suporte e legitimavam arranjos institucionais existentes.

Um aspecto relevante das novas abordagens sobre mudança institucional é o reconhecimento de que os indivíduos não são passivos. São atores que dão significado e vida às instituições, fazendo escolhas nas interpretações e na atribuição de significado às ações. Há os que destacam, entretanto, que os referenciais ou limites institucionais interferem na definição dos fins e moldam os significados mediante os quais os interesses são construídos e defendidos. De acordo com essa visão, qualquer agente ou fator de mudança estaria condicionado direta ou indiretamente por limites institucionais. Pode-se considerar, por outro lado, que há espaço para jogos de interesse autônomos e para improvisação nos limites institucionais, ou que existe uma inter-relação dialética entre atores, significados e ações (práticas e estruturas). E pode-se entender, ainda, que as instituições são potencialmente contraditórias entre si, e que os indivíduos e as organizações transformam as relações institucionais explorando essas contradições.

Abordando a relação entre organizações e ambientes institucionais, a proposta é entendê-los como imbricados, admitindo relativa autonomia e relativa dependência entre formas de organização e estrutura cultural e valores institucionais no centro das quais são constituídos. A interação constante, dinâmica e complexa entre organização e ambiente afasta a idéia de uma relação determinista e inequívoca. Boa parte dos trabalhos no campo revela, porém, uma perspectiva mais restrita, segundo a qual a vida organizacional pode ser vista como um permanente ajuste das organizações às pressões do ambiente.

Um tema clássico da teoria institucional nos estudos organizacionais é o dos mecanismos de isomorfismo, pelos quais dadas organizações tendem a reproduzir procedimentos aplicados em outras, adaptando suas práticas para responder às expectativas às quais se sentem vulneráveis. Esses mecanismos podem ser de natureza coercitiva, mimética, normativa ou indutiva, quando as mudanças ocorrem como resposta a incentivos ou prêmios. Um comportamento isomórfico pode ser adotado porque a organização busca autodefesa para problemas aos quais não pode ou não sabe construir soluções próprias. Mas é comum ocorrerem alterações pontuais, adotadas superficialmente como resposta a pressões, não representando mudanças profundas ou duradouras. Algumas vezes, porém, as organizações não copiam certas práticas por não terem sequer condições políticas, econômicas ou gerenciais para tal.

Os mecanismos de isomorfismo podem atuar tanto para a manutenção quanto para a mudança de valores e práticas no contexto institucional, mas a idéia básica é de que contribuem para a homogeneização de práticas, estruturas e processos organizacionais. Esse é um dos pontos aqui questionados, já que acreditamos que as práticas, as normas e os valores são resultado de uma produção coletiva em que a idéia vai sendo reelaborada ao ser apropriada, ao contrário da sensação relacionada ao isomorfismo, de que uma idéia ou prática nasce e difunde-se pronta, sem adaptações.

É comum que soluções em gestão pública que dão certo em uma determinada cultura ou contexto sejam adaptadas e aplicadas em vários locais pelo mundo como modelos de sucesso a serem copiados, por influência de organismos internacionais ou fundações financiadoras que atuam em vários países. E as idéias e os métodos recomendados freqüentemente são gerados em países com características muito diferentes de onde serão implementados. A ansiedade pelas fórmulas de excelência, benchmarks de competência ou modelos de sucesso do mundo dos negócios tem invadido o setor público nos últimos anos, gerando a tendência à padronização. Mas os modelos, conceitos e práticas cada vez mais disseminados podem não significar uniformidade ou opressão, já que Estados nacionais, organizações e gestores não são esponjas que absorvem tudo ou bonecos que apenas seguem padrões, mas atores que respondem a mudanças guiados por instituições existentes. 


\section{HERANCCAS INSTITUCIONAIS, MUDANÇA E ARTICULACÃO ENTRE O TRADICIONAL E 0 NOVO}

Muitas das análises sobre a herança que condiciona a cultura política no Brasil destacam características negativas, como clientelismo, corporativismo, patrimonialismo, formalismo e nepotismo, disseminando a idéia de que algumas delas são recorrentes e difíceis, ou até mesmo impossíveis, de serem superadas.

Entre os céticos, há os que crêem que nossa cultura política não está madura o suficiente para que as reformas fujam de fato a esse tipo de tradição. Fatores como as estruturas de poder, o sistema de representação política, o nível educacional e a baixa capacidade empreendedora de parte da população são apontados como heranças do processo de formação sociocultural da sociedade brasileira, que reforçam os mecanismos coercitivos e limitam a capacidade de transformação. Referindo-se ao Estado, são comuns perspectivas que enfatizam as idéias de ineficiência, corrupção, interesse pessoal dos funcionários públicos em detrimento do bem comum, e incorporação excludente e seletiva de interesses da sociedade civil nas ações do governo, motivando proposições de redução do Estado ao mínimo.

Embora algumas dessas crenças já tenham sido superadas, ainda predomina um clima de desconfiança em relação ao Estado e à administração pública. Uma decorrência disso é a construção de uma espécie de imaginário coletivo de ausência de perspectivas, de que tudo tem permanecido igual e nada jamais mudará, o que limita a percepção das possibilidades de transformação e ignora a complexidade do ambiente que influencia as estruturas. De- fendemos que é fundamental reconhecer que as instituições são passíveis de reforma, passando pela superação de características críticas e respondendo a novos desafios, e que abordar um problema a partir da perspectiva do atraso pode impedir a percepção de novas articulações. Isso não significa que esses elementos não permaneçam com maior ou menor intensidade ao longo do tempo e do espaço.

Vivemos um complexo e até contraditório processo de institucionalização de práticas inovadoras, que contribuem significativamente para superar condicionantes negativos da história de relações entre Estado e sociedade no Brasil. Admitese que as novas relações por vezes repetem e por outras contradizem características tradicionais. Nossa história mostra que as diferentes gramáticas de relação entre Estado e sociedade combinam-se de forma diversa, ganhando ou perdendo força em cada período histórico e situação específica.

As mudanças não ocorrem, portanto, em uma única direção, não são unívocas e previamente definidas. O novo e a reiteração do tradicional são movimentos coexistentes, e a perspectiva da diversidade deve estar incluída no interior do novo. Os estudos que tratam de mudança institucional publicados no fórum do Academy of Management Journal evidenciam as complexas maneiras pelas quais novas formas institucionais interagem com arranjos existentes para criar vários novos processos e estruturas, fugindo do isomorfismo. Os resultados caracterizam-se pelo hibridismo, combinando novos e velhos elementos por meio da bricolagem. E os movimentos sociais são apontados como objetos interessantes para se estudar a dinâmica da mudança, por se tratar de um campo no qual tem havido a introdução de novos atores e interesses, novos repertórios de ação e novos tipos de arranjos estruturais, incorporando organizações estabelecidas e emergentes, e processos de poder que misturam contenção, transgressão e autoridade institucionalizada.

Alertamos, ainda, para a necessidade de se considerarem variações culturais, históricas e sociais de cada região nas análises organizacionais. Vivemos na intersecção de vários mundos e vários períodos históricos, o que torna possível a emergência de formas descontínuas, alternativas e híbridas e o convívio do tradicional e do moderno, do popular e do culto, do local e do estrangeiro. Como observam Calás e Arias, referindo-se à América Latina, as organizações mesclam administração profissional e características de empresas familiares, tecnologias avançadas e relações de clientelismo, práticas avançadas de recursos humanos e paternalismo.

Em meio a esse debate, é fundamental considerar que nem sempre o novo significa algo melhor, mais apurado ou mais desenvolvido, enquanto o velho ou tradicional corresponderia a algo ruim ou atrasado.

Outro risco freqüente ao abordar temas complexos, como desenvolvimento, democracia e descentralização, é o de estabelecer relações causais restritas. Nas análises a respeito das causas do subdesenvolvimento de regiões e países, por exemplo, muitas vezes é atribuído um peso elevado a um único fator, em um modelo simplista pelo qual se entende que o subdesenvolvimento ocorre em função de X. Portanto, retirando-se $\mathrm{X}$, o resultado natural seria o desenvolvimento. Nesse sentido, percebe-se em certas análises o pressuposto que rotula regiões ou 
países como fadados a bons ou maus governos, como resultado de sua história, e com pouca chance de intervenção para transformações.

Um estudo muito debatido, conduzido por Robert Putnam na Itália, concluiu que as razões históricas e o contexto social condicionam profundamente o desempenho das instituições, indicando que uma sociedade civil vigorosa, com capital social bem constituído, leva a um governo forte, instituições com melhor desempenho e sociedades mais democráticas. E que o civismo e o desenvolvimento econômico são elementos que se combinam em um ciclo virtuoso de influência mútua. Segundo o estudo, porém, a história das instituições move-se lentamente, e são demorados os processos de criação de solidariedade, de senso de reciprocidade e civismo, os quais constituem o capital social.

A conclusão de que bons governos regionais foram encontrados onde a sociedade civil era mais desenvolvida leva à suposição de que as regiões sem um forte capital social estão fadadas ao mau governo ou, no mínimo, começam com clara desvantagem. Judith Tendler é uma das autoras que questionam essa associação automática, divulgando exemplos concretos que contrariam ou, ao menos, relativizam certas teorias sobre descentralização, participação e desempenho de governos locais.

Os defensores da descentralização acreditam que dela decorrem o fortalecimento do tecido social, a ampliação do espaço público, além dos impactos positivos sobre a gestão pública no âmbito local. A idéia é que políticas públicas formuladas e executadas localmente têm maior possibilidade de adequação às necessidades e diversidades da população, bem como de serem melhor controladas e avaliadas, possibilitando à comunidade participar como protagonista de seu próprio desenvolvimento. Os governos locais seriam melhores por estarem mais próximos dos cidadãos, ficando mais vulneráveis às pressões dos mesmos. Essa visão parte do pressuposto de que a descentralização é necessária para melhorar a qualidade do governo local, e que uma sociedade civil robusta é pré-requisito para um bom governo.

Tendler defende que a explicação de como os governos melhoram passa, no mínimo, pela causalidade nas duas direções - formação da sociedade civil e melhorias na qualidade do governo -, e que as relações são mais complexas do que pretendem alguns defensores da descentralização. Tal complexidade permite maior intervenção dos planejadores para o fortalecimento da sociedade civil do que a permitida por uma perspectiva determinista (path dependent). Assim, ainda que fatores de ordem estrutural e institucional possam representar obstáculos à mudança, variáveis derivadas de decisões políticas deliberadas podem ser decisivas para processos de transformação. Ou seja, é possível aplicar mecanismos de incentivo para transformações institucionais, de cima para baixo.

A experiência recente evidencia que nem todas as expectativas em relação à descentralização se confirmam no caso brasileiro. Demonstram o risco da associação automática entre descentralização e eficiência e entre descentralização e democracia. O debate sobre o tema vem assumindo um caráter menos apologético, evidenciando, pela prática, que há efeitos que contrariam o consenso pró-descentralização produzido nas décadas de 1970 e 1980.

Após uma fase de extrema valo- rização dos níveis locais de governo, há consenso crescente da necessidade de articulação local / regional / nacional, o que também demanda o desenvolvimento de instituições que permitam o trabalho coordenado entre níveis e áreas de governo e entre organizações de diferentes origens. Vários autores demonstram que descentralização sem coordenação e integração por meio de uma política nacional que contemple as especificidades locais compromete o processo e os resultados.

\section{EXEMPLOS DE MUDANÇA NA GESTÃO PÚBLICA LOCAL NO BRASIL ${ }^{1}$}

O processo de transformação pelo qual passa a gestão pública brasileira a partir da década de 1980 é influenciado por um conjunto de fatores de pressão, que podem ser divididos em duas agendas - a democrática e a neoliberal -, exigindo dos governos, ao mesmo tempo, mais democracia e mais eficiência.

Por um lado, a agenda democrática reivindicava novos direitos sociais e políticos, eqüidade nos resultados das políticas públicas e democratização nos processos decisórios, pela divisão de poder do governo federal com estados e municípios e por meio da construção de canais de participação da sociedade civil no processo de formulação das políticas, da implementação dos programas e do controle da ação governamental. A agenda neoliberal, por outro lado, ganhava força em função da crise financeira que atingia vários países e do movimento de questionamento dos Estados como provedores exclusivos de bens e serviços públicos e únicos responsáveis pelos problemas sociais. Pregava a redução do tamanho do Estado e 
mais eficiência, eficácia, efetividade e qualidade na prestação de serviços públicos.

Pela combinação desses e outros fatores, consolidou-se o movimento de descentralização do Estado e revalorização do local como espaço privilegiado de gestão da coisa pública, levando à intensa descentralização de recursos e atribuições. Isso provocou alterações profundas na natureza das relações intergovernamentais, partindo-se de um Estado quase unitário no regime militar para um Estado federativo de fato. Ao mesmo tempo, criaram-se espaços para novas formas de articulação com a sociedade civil e com o setor privado, tanto para a provisão de serviços públicos quanto para novas formas de solidariedade social, ampliando a responsabilidade pela coisa pública para além dos domínios estatais.

Vários são os exemplos que demonstram mudanças na forma de atuar dos governos e a formatação de novos arranjos institucionais, especialmente no âmbito dos governos locais. Destacamos aqui o Programa Gestão Pública e Cidadania, criado em 1996 por iniciativa da Fundação Ford e da Fundação Getulio Vargas em São Paulo - FGVEAESP -, o qual tem apoio do BNDES - Banco Nacional de Desenvolvimento Econômico e Social - e busca identificar, valorizar, premiar e disseminar práticas de governos subnacionais que sejam inovadoras e valorizem a cidadania.

Analisando participantes do programa, identificam-se tendências de mudança de atuação de governos subnacionais na área social em torno de dois eixos principais: novas políticas sociais e novas formas de gestão. No conteúdo das políticas, há mudanças na concepção sobre a natureza dos serviços prestados e novas respostas a novos desafios - ênfase à prevenção na área da saúde e à qualidade na educação, por exemplo -, ampliação dos espaços de cidadania, com atenção a minorias antes excluídas, bem como ampliação da esfera de ação do governo local, com programas de geração de emprego e renda, dentre outros.

Entre as novas formas de provisão e gestão de serviços públicos, observa-se a modernização da gestão, por meio de mecanismos de descentralização, democratização da gestão, formação e qualificação de servidores, valorização do funcionalismo, reforço a sistemas de apoio a decisões, implantação de sistemas de avaliação de desempenho, programas de qualidade e produtividade e redução de custos.

Como exemplo de articulação entre municípios, há inúmeros consórcios intermunicipais, especialmente nas áreas de saúde e de recursos hídricos, mas também em áreas como abastecimento e desenvolvimento regional. Entre os novos mecanismos de participação consolidados em muitos locais estão os conselhos municipais e estaduais e o orçamento participativo, bem como a incorporação e revalorização de organizações tradicionais, como associações de bairro, clubes de mães, grupos de jovens e da terceira idade, conselhos de pais nas escolas e muitos outros. Há vários exemplos de estruturas municipais ou regionais para participação popular no processo decisório em programas de gestão, planejamento, habitação, desenvolvimento urbano, cultura e segurança.

São elementos que apontam para a construção de redes institucionais que reúnem diversos atores, envolvendo articulações intersetoriais, intergovernamentais e entre Estado, mercado e sociedade civil. Tudo isso impacta as estruturas e a ação orga- nizacional, provocando mudanças intra e interorganizacionais e levando à formação de novos tipos de organizações, não só na esfera estatal, mas também na sociedade civil e no mercado, além de organizações que misturam agentes, características e objetivos dos três setores. E as iniciativas que envolvem parcerias ou alianças tendem a permanecer após mudanças de governo, evitando a descontinuidade na condução de programas e indicando maior grau de institucionalização.

É evidente que as práticas participativas e inovadoras não são verificadas de forma homogênea pelo país, variando até mesmo de um governo para outro no mesmo local. Muitos municípios sequer conseguem superar a dependência financeira do governo federal, sobrevivendo exclusivamente de repasses de recursos. Há lugares nos quais, apesar das condições prévias desfavoráveis, os resultados são surpreendentes na condução de políticas públicas, envolvendo parceiros, criando novas estruturas organizacionais, gerando alternativas de geração e gestão de recursos, demonstrando a ampla diversidade de possibilidades. Por outro lado, alguns casos já premiados pelo Programa Gestão Pública e Cidadania, considerados exemplares, algum tempo depois sequer existiam, pois tiveram dificuldade para se institucionalizar.

Em um país como o Brasil, são tantas as diferenças de condições de um local para outro que fica difícil imaginar elevados graus de isomorfismo. Muitas são as regras, as leis, os programas e projetos que conduzem à homogeneização, mas os contextos são tão desiguais e as relações de poder tão complexas que não é sensato esperar resultados idênticos ao longo do território e do tempo. É evidente que acontece isomorfismo, 
e certo grau de homogeneidade é mesmo necessário como base que garanta maior igualdade de condições. Mas apenas como base a partir da qual haja espaço para o diferente. E a inclusão de novos atores e novos arranjos organizacionais contribui para a redução da homogeneização, já que amplia os espaços de participação e as alternativas de gestão.

O próprio Programa Gestão Pública e Cidadania poderia ser encarado como mecanismo de isomorfismo, já que prêmios são legitimadores e incentivadores das práticas que premiam. Por outro lado, ao destacar como os níveis subnacionais de governo conseguem ser criativos, inovadores e fazer diferente com os mesmos recursos de outros demonstra exatamente o contrário: que as práticas não são homogêneas e nem determinadas, e que os caminhos são plurais e diversificados, incentivando a variedade de soluções.

\section{CAMINHOS PARA NOVOS ESTUDOS}

A partir do que foi colocado, defende-se a realização de pesquisas nas fronteiras entre estudos organizacionais e outras áreas das ciências sociais, ampliando o quadro analítico para a compreensão dos fenômenos organizacionais no campo da gestão pública. Entre os temas que motivam mais estudos estão a relação entre poder e instituições e a liderança, a qual é pouco tratada na abordagem institucional e parece ser relevante nas experiências de inovação local. Cabe compreender melhor quem são os principais agentes nos processos de mudança institucional da gestão pública brasileira, quais seus interesses e como agem para defendê-los, bem como qual é seu grau de autonomia em relação ao ambiente. Interessa estudar também a relação entre pressões democráticas, novos arranjos organizacionais e distribuição de poder, e como isso varia de um local para outro.

Vale aprofundar ainda o estudo de características organizacionais de estruturas de gestão pública que se multiplicam pelo país, como conselhos, fóruns, consórcios e câmaras intermunicipais. Pode-se observar como se relacionam com formas tradicionais de gestão pública, como se comportam frente aos mecanismos de pressão internos e externos, o quanto são homogêneas as estruturas e processos e o quanto são influenciados pelas características locais. Nesse sentido, cabe explorar a influência de organismos internacionais, de prêmios e incentivos de outros níveis de governo nas práticas e estruturas, do fortalecimento da democracia, da ampliação do conceito de cidadania e do desenvolvimento de canais de comunicação e participação cidadã nas práticas organizacionais.

\section{CONSIDERAÇÕES FINAIS}

O momento político em que vive o país e os exemplos aqui debatidos reforçam que é preciso acreditar na possibilidade de minimizar ou superar condicionantes históricos que dificultam um desenvolvimento mais justo e incentivar a mudança e a criação de instituições para sus- tentar esse desenvolvimento. Reforçam também a percepção de que as mudanças institucionais são resultado de diferentes combinações entre o novo e o tradicional e são raramente radicais. Revolucionário pode ser exatamente promover reformas graduais, respeitando instituições existentes e ampliando os espaços de comunicação, participação e cidadania, fortalecendo, assim, a grande instituição política moderna - a democracia, também esta em contínuo processo de reinvenção e re-significação.

Esperamos ter evidenciado que a aproximação entre os estudos de mudança institucional e a gestão pública brasileira pode gerar frutos relevantes tanto para a teoria quanto para a prática organizacional, já que esse processo em curso no país se constitui em campo fértil e desafiador para os estudiosos da mudança. Chamamos a atenção para a necessidade de ampliar o quadro analítico, considerando a história, o tempo, as especificidades locais e a combinação de características e interesses que definem a diversidade e a heterogeneidade das práticas organizacionais, as quais refletem e interagem com a complexidade das instituições que as envolvem.

\section{Pensata recebida em 14.06.2002. Aprovada em 27.05.2003.}

\section{Nota}

1. Esta seção é baseada, principalmente, em análises de Marta Farah a respeito de casos participantes do Programa Gestão Pública e Cidadania.

\section{Paula Chies Schommer Doutoranda em Administração de Empresas pela FGV-EAESP, Mestre em Administração pela UFBA-NPGA. E-mail: paulacs@gvmail.br}

